\title{
Ler e escrever, ver, ouvir e contar histórias em família: o caso de Pedro Nava (Minas Gerais, início do século XX)
}

\section{Read and write, see, listen and tell stories in the family: the case of Pedro Nava (Minas Gerais, early twentieth century)}

\author{
Juliana Ferreira de Melo ${ }^{1}$ \\ Ana Maria de Oliveira Galvão ${ }^{2}$
}

\begin{abstract}
RESUMO
Como uma criança das elites brasileiras constrói, em seu cotidiano, modos de participação nas culturas do escrito? De que maneira se dá a formação de um "herdeiro" em relação ao escrito no início do século XX? Para responder a perguntas dessa natureza, neste artigo, analisamos os eventos de letramento narrados pelo médico e escritor mineiro Pedro Nava (1903-1984) em suas Memórias. Fundamentadas em trabalhos da História Cultural, da Sociologia da Educação, da Teoria Literária e da Análise do Discurso, utilizamos a obra de Nava como principal fonte do estudo. Fruto de relações entre história e literatura, suas Memórias configuram-se como uma importante manifestação da formação do escritor. A pesquisa evidenciou que muitas das práticas de leitura e escrita vivenciadas por Nava na infância eram mediadas, na família, pela voz de seus parentes. Além disso, o aprendizado de certos gostos culturais relacionava-se com a sua admiração pelos valores e modos de viver de seus familiares. Assim, em seu processo de formação e autoinvenção, ele foi escolhendo o que receber da família. Como um "herdeiro", tal aprendizado não é apresentado como um esforço próprio, nem como um investimento contínuo, de longa data, de seus familiares na sua formação. O mundo das letras lhe chega como um elemento comum, aparentemente natural e não
\end{abstract}

DOI: $10.1590 / 0104-4060.37811$

1 Universidade Federal de Minas Gerais, Centro Pedagógico. Belo Horizonte, Minas Gerais, Brasil. Av. Antônio Carlos, nº 6627. CEP: 31270-901.

2 Universidade Federal de Minas Gerais, Faculdade de Educação. Belo Horizonte, Minas Gerais, Brasil. Av. Antônio Carlos, nº 6627. CEP: 31270-901. 
como o resultado de suas vivências em um ambiente propício à apropriação de preferências da cultura legítima de sua época.

Palavras-chave: culturas do escrito; herança cultural; leitura; escrita e oralidade; história da educação.

\begin{abstract}
How does a child from Brazilian elites constructs, in his everyday life, ways to participate in written cultures? How was the formation of an "inheritor" in the beginning of the $20^{\text {th }}$ century, regarding writing? To answer those kinds of question, this article analyses the literacy events narrated by the physician and writer from Minas Gerais, Pedro Nava (1903-1984), in his Memoir. This main source is analyzed using works of Cultural History, Sociology of Education, Literary Theory, and Discourse Analysis. A combination of history and literature, his Memoir is an important representation of his formation as a writer. The research showed that many of his reading and writing practices during childhood were mediated, in his family, by the voice of his relatives. Besides this, the learning of certain cultural tastes was related to his admiration for the values and ways of living of his family. Thus, in his process of formation and self-creation, he was choosing what to receive from his family. As an "inheritor" such learning is not presented as a personal effort, or as a continuous, long term investment of his family in his formation. The literate world reaches him as a common element, apparently natural and not as the result of his experiences in a favorable environment to the appropriation of legitimate culture preferences of his time.
\end{abstract}

Keywords: written cultures; cultural heritage; reading; writing and orality; history of education.

\title{
Introdução
}

Como uma criança pertencente às elites brasileiras constrói, em seu cotidiano, modos de participação nas culturas do escrito ${ }^{3}$ De que modo um indivíduo apropriou-se, nas primeiras décadas do século XX, da leitura e da escrita, no quadro de um conjunto de práticas de transmissão familiar? De que

3 Consideramos cultura escrita como o lugar - simbólico e material - que o escrito ocupa em/para determinados indivíduos, grupos sociais e sociedades (GALVÃO, 2010). Por isso, a opção por usar a expressão no plural: culturas do escrito. 
maneira se realiza a participação de um "herdeiro"4 no mundo da escrita? Para responder essas perguntas, investigamos o percurso de formação do médico e escritor mineiro Pedro Nava (1903-1984) no ambiente familiar.

De modo geral, as condições e os processos de inserção e participação nas culturas do escrito por indivíduos, provenientes de diferentes meios sociais, apresentam-se como um tema de pesquisa pouco explorado e pouco elucidado. Investigações sobre os processos que envolvem não só a transmissão de heranças aos indivíduos, como também sua apropriação por meio de práticas, conhecimentos e representações, demonstram que esses processos ocorrem sob condições históricas específicas, ainda pouco numerosos na História ${ }^{5}$, embora existam estudos que explorem essa temática na atualidade 6 . São ainda mais raros os estudos que revelam o papel da família nesses processos, sobretudo no Brasil, no início do século $\mathrm{XX}^{7}$.

No campo da Sociologia da Educação, desde a segunda metade do século XX, sobretudo a partir da década de 1960, muito se tem estudado e debatido a respeito das relações estabelecidas entre família, escola e as diversas classes sociais. Entretanto, de modo particular, os estudos sobre "herdeiros" tendem a considerar sua participação no mundo cultural como um processo quase natural e espontâneo devido às condições materiais sob as quais esse fenômeno costuma ocorrer, quando se trata de indivíduos originários, em geral, de meios sociais representantes da cultura dita legítima e/ou detentores de capital econômico ${ }^{8}$. Apesar disso, pesquisas realizadas nos anos 1990, como os estudos de François De Singly, mostram que, na mesma proporção em que há um esforço da família e da escola para transmitir capital cultural ${ }^{9}$ aos indivíduos, há também um trabalho de apropriação desse capital pelos sujeitos. Assim, embora exista certa opacidade que envolve as diversas maneiras de participação no mundo

4 Sobre o uso do termo "herdeiro", ver Bourdieu e Passeron (1967); os escritos de Bourdieu reunidos em um livro por Nogueira e Catani (1998); os estudos de De Singly $(1993,1996)$ e os de Lahire (2004, 2006).

5 Consultar, por exemplo, Hébrard (1996, 2000 e 2007).

6 Ver, por exemplo, Nogueira $(1995,1997)$ e a coletânea organizada por Nogueira, Romanelli e Zago (2000).

7 Estudos que exploram o papel da família nos processos de inserção e participação nas culturas do escrito por indivíduos, no início do século XX, no Brasil, não foram localizados, a não ser aqueles reunidos no livro organizado por Galvão et al. (2007). Na História da Educação, destacamos os estudos de Magaldi (2007).

8 Ao analisar o papel da Escola, na França, na segunda metade do século XX, na transmissão de saberes culturais aos estudantes, Bourdieu afirma: "Em todos os domínios da cultura, teatro, música, pintura, jazz, cinema, os conhecimentos dos estudantes são tão mais ricos e extensos quanto mais elevada é sua origem social. [...]” (BOURDIEU, 1998 [1966], p. 45).

9 Para uma discussão sobre capital cultural e sua manifestação em três estados (incorporado, objetivado, institucionalizado), ver Bourdieu (1998 [1979]). 
cultural e, mais especificamente, no mundo letrado, por indivíduos, famílias, diferentes grupos sociais, há poucos estudos que apreendem como ocorre esse processo de transmissão e de apropriação cultural. Nesse sentido, partimos do pressuposto de que os indivíduos os quais se comportariam como "herdeiros" não apenas recebem uma herança (cultural, econômica, simbólica, social), mas também realizam um trabalho de apropriação do capital (cultural, econômico, simbólico, social) que se busca transmitir a eles.

Em nosso estudo, utilizamos, como principal fonte a obra memorialística de Pedro Nava, escrita e publicada entre 1968 e 1984. Baseamo-nos, teórica e metodologicamente, em trabalhos da História Cultural, da Sociologia da Educação, da Teoria Literária e da Análise do Discurso. Fruto de relações entre história e literatura, as Memórias de Pedro Nava configuram-se como uma importante manifestação da trajetória de aculturação do escritor.

Oriundo de uma família intelectualizada, Pedro Nava foi médico por mais de 30 anos antes de se entregar à escrita memorialística. Mesmo escrevendo poemas nas décadas de 1920, 1930 e ainda que tenha vivido o Modernismo em Belo Horizonte, com escritores e pares, entre eles, seu amigo, Carlos Drummond de Andrade, a obra de grande fôlego, reconhecida pela crítica como um dos maiores exemplos, em Língua Portuguesa, no gênero memórias, só começaria a ser edificada por Nava aos 65 anos de idade. O mineiro de Juiz de Fora estudou no Colégio Andrés, em sua cidade natal; no Colégio Anglo Mineiro, em Belo Horizonte, e concluiu a escolarização básica no Colégio Pedro II, no Rio de Janeiro, para onde voltou, após finalizar sua formação na Faculdade de Medicina de Belo Horizonte. Atuou como médico reumatologista; foi professor catedrático e pesquisador. No Rio de Janeiro, viveu até a morte, em 1984, quando se suicidou. Nas suas Memórias, enfatiza que, na infância, aprendeu a amar as letras, os livros, a música erudita, a cultura legítima de sua época, disponibilizada a ele pela família de seu pai, o também médico, José Pedro da Silva Nava. Da família materna, marcaram Pedro Nava os cuidados de sua mãe e uma forte negação da herança de sua avó, uma mulher escravocrata e caracterizada, em sua narrativa, como dotada de grande crueldade, enriquecida pelo casamento com o fundador da cidade de Juiz de Fora, o engenheiro Halfeld.

Neste artigo, analisamos os eventos de letramento ${ }^{10}$ apresentados por Nava em suas memórias, com o objetivo de evidenciar o trabalho ativo do escritor para se apropriar de elementos da herança cultural familiar, tanto na época em que vivenciou as situações descritas, quanto no momento da escrita das memórias

10 De acordo com autores como Heath (1983), evento de letramento é toda e qualquer situação em que há a mediação da palavra escrita. 
(quando teve a oportunidade de se reinventar ${ }^{11}$ ). Em um primeiro momento, destacamos os episódios em que certa forma de oralidade ${ }^{12}$ - que se aproxima de lógicas tradicionalmente associadas ao escrito - é destacada como a principal dimensão da linguagem utilizada nas sociabilidades. Em um segundo momento, destacamos a presença de materiais escritos e os episódios de leitura e escrita por Nava vivenciados e, posteriormente, narrados como fundamentais em seu processo de aproximação das culturas do escrito.

\section{Oralidade, leitura e escrita}

Quando menino, Pedro Nava ouvia de sua família casos, histórias ${ }^{13}$, conversas. Em um ambiente com livros, revistas, jornais, estantes, escrivaninhas, instrumentos musicais, partituras e o convite, sobretudo por parte de seus parentes paternos, para que também ele se envolvesse em práticas de leitura e escrita, a oralidade estava sempre presente. A voz, no ramo paterno da família do escritor, era não somente um instrumento para transmitir às gerações mais novas princípios valorizados pelo grupo e que caracterizavam seus ancestrais, mas também o meio pelo qual seus familiares comentavam, além de fatos cotidianos, as leituras que realizavam ou a escrita que produziam ${ }^{14}$.

As conversas que constituíam as sociabilidades da família de Pedro Nava organizavam-se, comumente, em torno de textos escritos de diferentes gêneros. Literários ou não, publicados em jornais e revistas, esses textos (lidos ou que seriam lidos após os encontros entre familiares e amigos) apresentavam-se como o eixo das conversas. Os espaços de sociabilidade dos parentes de Pedro Nava e do próprio escritor, quando menino, caracterizavam-se, portanto, por serem ambientes em que oralidade e escrita estavam intricadas, uma engendrando a

11 Sobre a (re)invenção de si, ao narrar a própria experiência, consultar Bourdieu ([1986] 1996).

12 Consideramos, a exemplo de diversos autores que têm norteado a realização de pesquisas no campo da história da cultura escrita, oralidade e escrita de modo não dicotômico. Ver Galvão e Batista (2006) e Galvão (2010).

13 Neste artigo, não apresentaremos a experiência de Nava com contadores de histórias, principalmente Rosa.

14 Segundo Ginzburg (2006 [1976], p. 13), "a cultura das classes subalternas é (e muito mais, se pensarmos nos séculos passados) predominantemente oral”. Mas em qual medida a oralidade não se apresenta, de maneira complexa e intricada, como constituinte também da cultura das elites? Para Candido (1980), o Brasil, no início de século XX, seria um país de auditores e não de leitores. 
outra. Conversas que aconteciam em gabinetes, escritórios; encontros em que se debatiam política, abolição da escravatura, literatura, o que se deveria publicar nos jornais não eram raros nas casas dos parentes de Nava.

Juntamente com a imersão em ambientes onde circulavam impressos, livros, jornais, cadernos de colagens e anotações, revistas, Nava viveu também envolvido pela conversa a respeito dos livros. Sua intimidade com a cultura escrita foi se tornando, ao longo da vida, de tal modo forte que, na sua memória (ou em suas Memórias), ficaram impressas as histórias ouvidas de seus parentes como se elas tivessem sido lidas por ele na infância: "Era sempre nessa dependência - meio sala, meio escritório - que nossa família se reunia para conversar. A Marout gostava de evocar a história de Carleto, Roca e dos mancebos esganados. Foi meu primeiro folhetim de sangue... [...]" (NAVA, 2002, p. 332).

$\mathrm{Na}$ interpretação de Nava, escritor adulto, a história contada pela tia-avó paterna ganha contornos de um texto escrito: o folhetim, gênero textual que era publicado, por capítulos - em geral de romances -, em jornais, durante o século $\mathrm{XIX}^{15}$. Desse modo, a reunião de todos os folhetins publicados no impresso configuraria o enredo completo de uma trama. No caso das histórias ouvidas por Pedro Nava, as histórias "de sangue" chegavam a ele por meio de seções em que os parentes narravam pedaços de uma trama, capítulo por capítulo, como se estivessem impressas e publicadas em jornais, na forma de um folhetim. Em outras palavras, Nava se vale de um conceito próprio da cultura escrita para falar de sua experiência como ouvinte de narrativas que ele só conheceria por meio do impresso, pela leitura, mais tarde.

Oralidade e escrita misturam-se no mundo letrado. As evidências desse fenômeno estão não apenas no tecido textual das Memórias, no vocabulário que o escritor usou para (re)significar as experiências de contato com as narrativas, mas também nos eventos do passado, na escolha dos parentes por determinados espaços em que a família de Nava reunia-se para conversar. Para "evocar" histórias, opta-se pelo cômodo da casa que se aproxima de um escritório. Esse cômodo costuma ser o espaço onde os moradores de uma casa guardam seus livros, seus papéis, os objetos que utilizam ao lidar com a escrita; onde estudam e trabalham quando o ofício relaciona-se de alguma forma com a leitura e com a escrita.

As histórias de Napoleão Bonaparte e Dom Quixote também chegariam a Pedro Nava, na sua infância, por meio da oralidade. Apoiando-se no livro, Antônio Salles contava para o sobrinho histórias que ele mesmo já conhecia, que ele mesmo já teria lido:

15 Para uma história sobre o folhetim, ver Meyer (1996). 
Quando voltei para casa corri à sala de visitas. Não havia [...] sala de visitas. Tinham tirado vários móveis, posto uma cama larga, um armário e improvisado dormitório; tio Salles e tia Alice tinham chegado do Ceará. Ia ser tempo de figura em livro e de uma história saindo de cada estampa. Foi quando conheci Napoleão Bonaparte, Dom Quixote e Sancho Pança. Tio Salles apresentou-me os três no mesmo dia. O primeiro, de bandeira na mão, passando a Ponte de Arcole. O segundo, recebendo a pranchada de cavaleiro, tendo para pôr à cabeça a bacia de barbeiro que era o elmo de Mambrino. O último, tal qual balão, sendo levitado pelas cobertas brandidas pela canalha hílare do pátio da estalagem (NAVA, 2002, p. 317).

As imagens, as figuras, as ilustrações que já encantavam Pedro Nava quando menino serviam como base para a memória do tio, que usava as estampas dos livros para contar histórias ao sobrinho. Narrativa oral cruzava-se, desse modo, com elementos da cultura escrita, e o gosto de Nava pela descoberta de histórias ia se construindo graças ao que ele ouvia. Logo, a oralidade o familiarizava tanto com objetos da cultura escrita quanto com modos de organização de um texto escrito (oralizado).

Quando a conversa não era organizada em torno da leitura prévia de um livro, o tema era, frequentemente, a política:

[...] Tio Salles contava estas histórias tremendo de indignação e elas levavam-no a seu assunto favorito - o velho Accioly. Ia logo buscar as laudas do livro que estava escrevendo e que devia ser o complemento e a continuação do libelo Frota Pessoa. Lia alto. Era a crônica das violências, das pancadas, das mortes, dos exílios, das perseguições e das patotas que se desenrolavam no seu estado natal. Eu de tanto ouvir falar em Accioly e nas maldades de Accioly, acabei dando dimensões sobre-humanas ao oligarca. [...] (NAVA, 2002, p. 335).

Elemento comum nas narrativas orais, a performance de quem conta a história contribui para a memorização da narrativa por parte de quem a ouve ${ }^{16}$.

16 Para Zumthor (1993, p. 139), a voz assumiria "uma função coesiva e estabilizante sem a qual o grupo não poderia sobreviver". Quando as pessoas contam histórias a outras, quem ouve passa a ter uma imagem que não se apaga, mesmo que o tempo e os interlocutores, aqueles que contam histórias e casos, tenham passado. Isso ocorre porque ela reúne narradores e ouvintes, os interlocutores "num instante único - o da performance -, tão cedo desvanecido que se cala; ao menos, produz-se essa maravilha de uma presença fugidia mas total” (p. 18). 
Vendo o tio tremer de indignação, ao contar os casos relacionados ao quadro político brasileiro, do Ceará, Pedro Nava teve mais chance de não se esquecer do que era discutido nos encontros entre seus parentes, tampouco do que acontecia nesses encontros. A análise de sua narrativa mostra-nos como fatores que caracterizam eventos orais misturam-se com fatores característicos do mundo da escrita. No exemplo citado, percebemos o tio de Pedro Nava envolto nos casos a respeito dos quais falava, que o fazem trazer para o contexto da conversa as páginas do livro que ele estava escrevendo. Para apresentar seus escritos aos participantes da conversa, no lugar de dar a cada um uma página para a leitura individual, lê, ele mesmo, em voz alta o que já havia produzido. Valendo-se de sua voz, Antônio Salles oferece aos ouvintes o contato com a sua escrita, o relato (e a sua interpretação) do governo Accioly.

Temos, nos exemplos analisados, uma relação estreita entre oralidade e escrita, entre voz e material impresso ou manuscrito que, paulatinamente, foi familiarizando Pedro Nava com o mundo das culturas do escrito. Esse mundo foi sendo conhecido pelo autor graças à convivência, com esse universo, propiciada pela voz do outro ${ }^{17}$.

\section{Vivendo em contextos marcados pela presença de materiais escritos, impressos e práticas letradas}

Estudos contemporâneos ${ }^{18}$ mostram que um dos fatores que mais favorecem a formação de pessoas que utilizam, com desenvoltura, a leitura e a escrita é ter vivido o contato, ainda na infância, com uma pluralidade de materiais escritos, principalmente na família. Como pudemos evidenciar no tópico anterior, de acordo com a análise das Memórias de Pedro Nava, os parentes com quem o futuro memorialista convivia nas primeiras décadas do século XX possuíam uma rotina em que o material escrito estava sempre presente. $\mathrm{O}$ escrito parecia ocupar um lugar tão importante nas sociabilidades familiares que, nas descrições das casas dos parentes paternos, há sempre um ou mais cômodos diretamente a ele associados.

17 Galvão (2002), em seu estudo sobre os ouvintes de cordel em Pernambuco, entre as décadas de 1930 e 1950, mostra como analfabetos participavam da cultura escrita mesmo sem saber ler e escrever. Também Soares $(1998,2003)$ mostra como pessoas que ainda não dominam a tecnologia da escrita envolvem-se em eventos de letramento.

18 Ver, por exemplo, a coletânea de artigos, organizada por Ribeiro (2003), a respeito do letramento no Brasil, a partir da análise de dados do Indicador Nacional de Alfabetismo Funcional (INAF) 2001. 
Trabalhando em casa, o pai de Nava propiciava ao filho a visita constante ao seu gabinete médico. Nesse cômodo, tanto os móveis e os objetos ligados à Medicina prendiam a atenção do menino, quanto os materiais escritos: livros, anúncios, calendários. No escritório de José, dois campos comuns nos espaços de convivência de Nava se cruzavam e se entrelaçavam: a Medicina e a cultura escrita.

O escritório de meu Pai era separado do corredor por um tabique envernizado. [...] Por dentro, encostada ao tabique, a escrivaninha e a mesa de examinar doentes, toda de palhinha e estilo austríaco. À esquerda, duas estantes de livros e à direita, os armários com os ferros e os remédios. Vinha daí esse cheiro especial de drogas e de cânfora que tem sido o cheiro de minha vida: cada vez que o sinto recaio no gabinete médico de meu Pai e vejo nos seus lugares o retrato de Francisco de Castro ${ }^{19}$ e os painéis de anúncio das Tabletas de Antikamnia que eram o "oposto à dor", que não induziam ao "hábito das drogas". Não se esqueçam, pastilhas Antikamnia de 30 centigramas - Analgésico, anódino, da Companhia Química de Antikamnia, 1622 Pine Street, St. Louis, Mo., E.U.A. Canalhas de americanos! já naquela época... Estes anúncios eram os calendários de 1906, 1907 e 1908. [...] (NAVA, 2002, p. 224, grifo do autor).

Além do gabinete do pai, o quarto das tias é, na memória de Nava, associado diretamente à sua formação como leitor e escritor: "Mas o mais importante desse quarto de minhas tias é que nele, além dessa marca médica, eu tive outra. Ali se me desabrochou amor que nunca me deixou. $\mathrm{O}$ amor dos livros, o amor da leitura. [...]" (NAVA, 2002, p. 353). Nava ia, assim, incorporando a herança familiar que lhe era disponibilizada, seja em relação ao campo profissional, seja em relação a determinadas práticas culturais que caracterizavam, em grande medida, o ramo paterno de sua família. Aos poucos, Nava também ia construindo o seu próprio espaço para ler e escrever. $\mathrm{O}$ quarto que se ligava à sala de livros da tia Cândida, além de ser o lugar da casa em que o menino assistira às intervenções médicas de seu pai quando José cuidara da sobrinha, era também o lugar que ele escolhera para ler e se divertir com $O \operatorname{Malho}^{20}$ e a $\operatorname{Careta}^{21}$ :

19 Professor do pai de Pedro Nava, figura muito importante na formação médica de José.

20 Para um estudo sobre $O$ Malho, revista semanal ilustrada, destinada ao grande público, ver Vergueiro e Santos (2005).

21 Publicação carioca, a Careta foi uma revista ilustrada, editada na primeira metade do século XX. Mauad (2005, p. 152-153), ao analisar as imagens fotográficas desse impresso e de outros, concluiu que esses suportes seriam veículos os quais criariam "modas" e imporiam "comportamentos, assumindo a estética burguesa como a forma fiel do mundo que representavam". 
[...] Ignoro as razões obscuras que me fizeram erigir o quarto lateral do nosso sobrado em sala de leitura. O silêncio? a claridade? sua janela aberta para as nuvens que passavam? Sei que para lá eu carregava exemplares do Malho e da Careta, onde me deleitava com os desenhos, as fotografias e ia soletrando, na última, penosamente, as Cartas de um Matuto, onde eram contadas, em verso, as bestidades do Tibúrcio da Anunciação. [...] (NAVA, 2002, p. 354).

O quarto que lhe despertava o gosto pela Medicina era também o espaço em que Nava ia construindo seu gosto pela leitura. Vivendo sua fase de alfabetização, divertia-se com as revistas. Muito provavelmente, a claridade, o silêncio, a vista para o céu, cujas nuvens com frequência encantam as crianças, somados ao prazer que o menino tinha ao ver os desenhos e as fotografias que ilustravam esses suportes contrabalançavam sua dificuldade com o texto escrito em versos. Em outras palavras, no lugar de a leitura representar para Nava, quando menino, um sofrimento, já que ele ainda soletrava "penosamente" as palavras, mergulhar nas "Cartas de um Matuto" era antes um desafio, apesar de tudo, agradável.

Na casa de sua avó materna, Nava também tinha contato com objetos escritos. Mesmo que a maior parte dos seus parentes maternos não se mobilizasse para lhe apresentar o mundo da escrita, os livros que existiam na casa de sua avó Maria Luísa chamavam-lhe a atenção. Herança do engenheiro Halfeld à sua avó, os livros destacaram-se de tal modo para o memorialista que não foram descartados na escrita de suas reminiscências da infância e constituíram mais um elemento por ele tomado para explicar a sua "vocação" para se tornar um grande leitor e escritor: "[...] Pelos livros deixados, julga-se da competência, da cultura, do bom gosto e da civilização do alemão. [...]” (NAVA, 2002, p. 127). Adulto, conhecedor dos "bons" livros, do que podem revelar as leituras sobre a formação de alguém, Pedro Nava reconhece, nas Memórias, o valor dos livros de Halfeld como indicadores da cultura e do "bom gosto" do primeiro marido da avó materna.

O contato com uma pluralidade de materiais escritos - livros, jornais, revistas, cartões postais, documentos - não se dava, no cotidiano de Pedro Nava, de maneira contemplativa. O menino não apenas presenciava eventos de leitura e de escrita, como também participava ativamente deles. Desde muito cedo, era-lhe permitido manipular, produzir materiais escritos e deles se apropriar. Quando ainda não era alfabetizado, folheava e cortava revistas que ganhava de presente de suas tias: 
[...] Eu tinha diante dos olhos o exemplo de meu Pai, de suas irmãs, de seus cunhados, permanentemente atracados num volume da coisa impressa. Não possuía noção de leitura e já minhas tias mandavam para Juiz de Fora revista infantil que eu folheava e cortava. Vejo isto numa carta escrita por meu Pai a 22 de fevereiro de 1908, agradecendo a remessa de publicação chamada Fafasinho. Viveu só dois anos, 1907 a 1908. Não conheceu o destino de $O$ Tico-Tico ${ }^{22}$, que durou mais de meio século, 1905 a 1959. [...] (NAVA, 2002, p. 353-354).

Ainda que não dominasse a tecnologia do ler e do escrever, Nava convivia com materiais escritos em sua casa e com os usos que deles faziam seus parentes. A leitura e a escrita compunham o cotidiano de seus familiares e engendravam muitas de suas relações. No que se refere especificamente à leitura, são várias as cenas reconstruídas por Nava para mostrar como vivenciava momentos desse tipo na socialização familiar.

O cotidiano de sua tia Cândida era acompanhado de perto por Pedro Nava na casa da Rua Aristides Lobo. Durante parte do dia, ela dava lições de piano no colégio em que estudava a filha, e, o restante das horas de seus dias, passava lendo ou absorvida pela música:

[...] Minha tia voltava do Sacré-Coeur pelas quatro horas e passava o resto do dia ao piano ou agarrada aos livros. Eu gostava de admirá-la entregue a esses misteres e fascinava-me a capa de uma de suas coleções de romances, parece-me que chamada Horas de Leitura, onde havia uma dorida figura de senhora lendo e destacando seu perfil agudo e o luto de sua roupa contra a claridade de uma janela ao fundo. Parecia minha tia e comecei a amar os livros. [...] (NAVA, 2002, p. 323-324).

Pedro Nava, que, na época em que morou pela primeira vez no Rio de Janeiro, estava com aproximadamente oito anos, já gostava, de acordo com a sua reconstrução do passado, de observar a tia tocando piano ou entregue a suas leituras. $\mathrm{O}$ que encantava o menino era, especialmente, a materialidade de uma das coleções de romances de Cândida. Deixava-se fascinar pela capa dos livros de sua tia, imerso que estava em um mundo em que eles eram muitos.

22 Semanário que circularia, no Brasil, a partir de 1905, a revista almejava o mesmo prestígio gozado pelos livros destinados às crianças uma vez que publicava contos e poesias de autores consagrados, bem como anunciava novidades da literatura infantil. Ver, entre outros, Vergueiro e Santos (2005). 
Nava identifica, nas leituras de sua tia Cândida, um "bom gosto" que, em seu processo de reconstrução de si, influenciaria o escritor na vida adulta:

[...] Anos depois identifiquei as mesmas ilustrações, lendo Maupassant, Daudet, Mirbeau. Foi como um encontro de sombras da infância quando deparei com os desenhos de Vallet e Jeanniot em Mademoiselle Fifi e Boule de Suif; os de Rossi e Myrbach em Jack e Sapho; outra vez os de Jeanniot e os de Carrey no Le Calvaire e em Sébatien Roch. Eles me deram as chaves da literatura da tia - de suas boas leituras, do seu bom gosto. [...] (NAVA, 2002, p. 351, grifos do autor).

$\mathrm{Na}$ infância, Nava não sabia que as figuras das Horas de Leitura de sua tia ilustravam os escritos de Maupassant, Daudet, Mirbeau. Entretanto, o contato frequente com os romances de Cândida, com os livros de sua pequena sala familiarizava o menino com a literatura que ele leria mais tarde. Apesar do espanto do leitor já adulto com o encontro com os desenhos, as "sombras da infância", a intimidade de Nava era tamanha com os textos que ele "apenas" entendia, no momento da leitura de Mademoiselle Fifi, Boule de Suif, Jack, Sapho, Le Calvaire, as opções de sua tia, "naturalmente", "boas leituras", leituras de "bom gosto".

Pedro Nava foi se transformando, pouco a pouco, em um leitor bem estabelecido nas culturas do escrito. Adquiriu e desenvolveu competências e habilidades que o permitiam ler intensamente e materiais diversificados, o que pode ser evidenciado pelas inumeráveis e diferentes referências a que recorreu na produção das Memórias. Além da vasta intertextualidade com os escritores clássicos da literatura universal e com os autores de textos médicos, encontramos, em sua obra memorialística, referências a vários jornais, revistas, livros que tratam de estudos, mais ou menos localizados, do campo da História e da Geografia.

Em relação à escrita, desde muito cedo os parentes de Pedro Nava disponibilizavam para ele "cadernos e cadernos" em que o menino ia enchendo as suas páginas com desenhos e garatujas. Cadernos, lápis, tempo e espaço para a escrita estavam presentes na vida de Nava desde a infância. Na idade adulta, no momento de escrever suas memórias, esses elementos fazem naturalmente parte do cenário o qual, no momento da escrita da narrativa, ele (re)compõe. Nesse processo de (re)composição do passado, as peças do puzzle são encaixadas no espaço da escrita à medida que os sons de palavras, antes, na infância, representadas com desenhos, agora são representadas com letras que se unem no grande quebra-cabeça da escrita das Memórias. 
$\mathrm{Na}$ infância, Nava também observava seus familiares em constante ato de escrita. $\mathrm{O}$ trabalho de escrever parecia, entre seus parentes, tanto associado a necessidades pragmáticas (como, por exemplo, as anotações que resultavam dos estudos de seu pai para os concursos de médico legista que faria no Rio de Janeiro) quanto aos sentimentos. Enquanto viveu com os pais, os irmãos, com tio Salles e as tias paternas no Rio, entre os anos de 1910 e 1911, Nava presenciava todo o processo de escrita do tio. O trabalho de Antônio Salles sobre um poema que ofereceria à Alice, sua mulher, envolvia a escrita, a leitura, a oralidade:

[...] Todas as manhãs ele sentava-se cedo a essa mesa e escrevia até as dez, onze horas. Riscava, corrigia, lia baixo, rasgava, recomeçava; relia, rasgava outra vez, tornava a principiar, lia alto, retomava, até engastar o fecho de ouro na ourivesaria difícil do soneto ou do poema. Aí ele respirava aliviado, deixava cair a lima, o camartelo, o cinzel e acendia meio charuto. Em torno dele, a musa adejava com gestos precisos e silenciosos, nítidos e inaudíveis como o bater de asas de borboleta. Vem ver se está bonito, minha filha... Estava. E ela pagava com um beijo (NAVA, 2002, p. 318).

Destacamos ainda um aspecto que se encontra no entrelugar da leitura e da escrita na trajetória de Pedro Nava. Em muitos momentos de suas Memórias, o autor recorre a leituras que fez ao longo da vida para reconstruir e ressignificar espaços de sua infância e situações vividas naquela época. A ficção literária entra em cena, evidenciando, mais uma vez, como, por meio da leitura, Pedro Nava se apropriou de narrativas, como a de Eça de Queirós, para ressignificar espaços de sua infância, como o de sua casa em Juiz de Fora:

[...] quando li $O$ Primo Basílio coloquei a ficção queirosiana na Rua Direita 142 e jamais pude escapar desse sortilégio nas releituras. As salas se adaptavam perfeitamente à descrição do livro e os desabafos de Jorge com o Sebastião eram no escritório de meu Pai; D. Felicidade, O Conselheiro, Julião e o Ernestinho tomavam chá na nossa sala de jantar, na nossa louça, Juliana recebia as cartazinhas no alto de nossa escada. Luísa morreu no quarto de minha Mãe (NAVA, 2002, p. 226-227, grifos do autor).

Vale observar que essa associação entre realidade e ficção nos fornece elementos para construir um perfil de Pedro Nava não só como escritor, mas 
também como leitor. Se, do ponto de vista de sua narrativa, podemos considerar a intertextualidade com obras clássicas da literatura universal como uma estratégia discursiva utilizada pelo memorialista na composição de seu texto, é também a intertextualidade que nos oferece dados para delinear o tipo de leitor que Nava se tornou. Seu trabalho de citação, as relações que estabelece entre os capítulos de sua vida com os livros que leu nos fornecem uma medida de suas leituras, o quanto o escritor pôde navegar também como leitor pelas entranhas dos textos com que interagiu. A intertextualidade nos dá mostras, pois, de como Pedro Nava se apropriou do que leu. Sua apropriação dos textos como leitor, sugerida pelas Memórias, evidencia que, para atribuir sentido a suas leituras, Nava recorre à sua própria experiência, à sua própria vida, às pessoas e às personagens que o cercaram: "[...] Quando li As Minas de Salomão dei à bela Fulata a figura gentil de Rosa [...]" (NAVA, 2002, p. 227). Como escritor, movimento inverso aconteceria. Para (re)construir e compreender o (seu) passado, Pedro Nava vai à literatura e reconhece lá os personagens da sua história.

Das Minas de Salomão aos poemas de Edgar Allan Poe, Nava continua sua busca pelas personagens de sua história: “[...] $\mathrm{Abria}^{23}$ ao meio os cabelos mortiços e abundantes; tinha aquele ar sério e atento dos adolescentes que pressentem a terrível presença. Seus olhos luminosos, seu aquilino hebraico, sua beleza espectral fizeram-me identificar sua figura com a de Roderik Usher, quando vim a ler os contos de Edgard Poe. [...]" (NAVA, 2002, p. 321). A literatura é, assim, lugar privilegiado para o reconhecimento de personagens da vida que fora real na história de Pedro Nava, mas é também um espaço rico e importante no reconhecimento do próprio autor na e para a escrita memorialística:

[...] Depois dessa série de atos gratuitos e delitos inúteis, voltei para casa. Raskolnikov. O mais estranho é que houve crime e não castigo. Crime perfeito. Ninguém desconfiou. Minha avó não deu por falta da sua cédula. Eu fiquei por conta das Fúrias de um remorso que me perseguiu toda a infância, veio comigo pela vida afora, com a terrível impressão de que eu poderia reincidir porque vocês sabem, cesteiro que faz um cesto... Só me tranqüilizei anos depois, já médico, quando li num livro de psicologia infantil que só se deve considerar roubo o que a criança faz com proveito e dolo. O furto inútil é fisiológico e psicologicamente normal. [...] (NAVA, 2002, p. 261).

23 Aqui Pedro Nava está se referindo a um de seus parentes paternos, Iclirérico Neto, que costumava visitar a família na Rua Aristides Lobo, enquanto o memorialista morou no Rio de Janeiro, com seus pais e irmãos. 
Dessa vez, Dostoieviski é um dos autores privilegiados para a retomada dos delitos da infância, época em que, evidentemente, Pedro Nava não conhecia esse escritor. Nesse sentido, é importante ressaltar, mais uma vez, que sua experiência de leitor (e escritor) maduro é o que contribui com a construção de sua narrativa. Logo, na comparação tecida nas Memórias, Nava associa o enredo de Crime e Castigo às suas ações de menino, as quais não o deixariam durante boa parte da vida. Para (re)significar o remorso experimentado na infância pelo roubo do dinheiro da avó materna para comprar um livro e uma lâmpada elétrica, como um adulto que volta ao tempo de menino, o memorialista faz referência às "Fúrias", personagens da tragédia grega, a fim de atribuir sentido à culpa que o teria "perseguido", ao castigo advindo da consciência. Por fim, para dar aos acontecimentos de sua época de menino a dimensão que eles tomariam depois de anos de sofrimento com os delitos cometidos, Pedro Nava sai da literatura e busca apoio em um campo especializado, na psicologia infantil. Entre realidade e ficção, o passado de Pedro Nava ganha sentido nas Memórias; ganha novos sentidos para o próprio escritor.

\section{Considerações finais}

Uma primeira constatação a que chegamos, após a análise das Memórias, é que muitas das práticas de leitura e de escrita dos parentes de Pedro Nava eram motivadas pelas conversas, eram mediadas pela oralidade. Desse modo, no espaço das sociabilidades familiares, também Pedro Nava, durante a sua infância, sempre esteve mergulhado em um mundo em que a escrita era intermediada, muitas vezes, pela voz. Muitos dos elementos das culturas do escrito chegavam ao menino porque ele ouvia cotidianamente seus familiares falarem de histórias, seja de parentes seus, seja de personagens, que só poderiam se encontrar nos livros que foram também, em grande medida, os livros de sua vida, tal como evidencia a intertextualidade, um dos fundamentos da composição de suas Memórias. Constatamos, portanto, que não se pode dicotomizar, mesmo quando estudamos a formação intelectual das elites, as palavras oral e escrita.

Verificamos também que a construção e o aprendizado de Pedro Nava de certos gostos e preferências culturais, particularmente no que se referem à leitura e à escrita, relacionavam-se diretamente com a sua admiração pelos valores, comportamentos, modos de viver de seus familiares. Assim, desde a infância, Pedro Nava aprendeu a gostar de ouvir histórias; folhear, ler e recortar revistas; ler livros; desenhar e escrever frases que se conjugavam com suas ilustrações. 
Desde muito cedo, Nava aprendeu a valorizar a literatura universal e clássica, as artes plásticas, a pintura, o cinema não somente porque os parentes que ele amava apresentavam-lhe esse mundo da cultura dita legítima, mas também porque, eles mesmos, eram leitores fluentes; escreviam textos diversos; apreciavam a arte e faziam com que seus produtos estivessem presentes em seu dia a dia. Aliados, o incentivo à construção do gosto pela leitura, pela escrita e da preferência pela arte, bem como a admiração, o afeto do menino especialmente pelos parentes paternos, estavam constituídas, então, as condições propícias para que Pedro Nava gostasse das práticas culturais das quais gostavam também seus parentes queridos, bem como estavam aí lançadas as possibilidades para que ele se tornasse um indivíduo que cultivaria o capital cultural recebido inicialmente da família. Por meio da análise das suas Memórias, é possível afirmar que Nava não apenas vivenciou essas situações quando era criança, mas escolheu herdá-las, tornando-as partes constitutivas de si próprio, em seu processo de autoinvenção.

Outro ponto que merece destaque diz respeito à suposta "naturalidade" com que Pedro Nava fala da origem de seu amor pelos livros. Em sua reconstrução do passado, no tecido da narrativa, parece não haver modo de ele não gostar dos livros. Em uma espécie de transferência de amor (da afetividade que nutria por alguns de seus parentes paternos), Pedro Nava teria passado simplesmente a amar os livros. Para o escritor, que, nesse sentido, comporta-se como um "herdeiro", amar os livros fazia parte do curso natural dos acontecimentos de sua vida e não se apresenta a ele como um aprendizado contínuo, de longa data. O mundo da leitura lhe chega como mais um elemento comum, espontâneo e não como o resultado de suas vivências em um ambiente propício para a construção desse gosto. A análise minuciosa das Memórias, no entanto, revela-nos que, de um lado, havia um trabalho cotidiano e sistemático por parte dos familiares de Nava para que ele se tornasse um leitor e escritor; por outro, havia, por parte do autor, um trabalho ativo para receber parte da herança legada - principalmente a identificada com leituras e escritas de prestígio, aquela dos parentes paternos -, tornando-a parte de si mesmo.

\section{FONTES CITADAS}

\section{As Memórias}

NAVA, Pedro. Balão Cativo (memórias 2). São Paulo: Ateliê Editorial; Editora Giordano, 2000. 
NAVA, Pedro. Chão de Ferro (memórias 3). 3. ed. São Paulo: Ateliê Editorial; Editora Giordano, 2001.

NAVA, Pedro. Baú de Ossos (Memórias). 10. ed. São Paulo: Ateliê Editorial; Editora Giordano, 2002.

NAVA, Pedro. Beira-mar (memórias 4). 5. ed. São Paulo: Ateliê Editorial; Editora Giordano, 2003a.

NAVA, Pedro. Galo-das-trevas: as doze velas imperfeitas (memórias 5). 5. ed. São Paulo: Ateliê Editorial; Editora Giordano, 2003b.

NAVA, Pedro. O Círio Perfeito (memórias 6). 5. ed. São Paulo: Ateliê Editorial; Editora Giordano, 2004.

NAVA, Pedro. Cera das Almas (memórias 7). São Paulo: Ateliê Editorial; Editora Giordano, 2006.

\section{REFERÊNCIAS}

BOURDIEU, Pierre [1986]. A ilusão biográfica. In: AMADO, Janaína; FERREIRA, Marieta Moraes (Coord.). Usos e abusos da história oral. Rio de Janeiro: Editora da Fundação Getúlio Vargas, 1996. p. 183-191.

BOURDIEU, Pierre [1966]. A Escola conservadora: as desigualdades frente à escola e à cultura. In: NOGUEIRA, Maria Alice; CATANI, Afrânio (Orgs.). Pierre Bourdieu: escritos de educação. 8. ed. Petrópolis: Vozes, 1998. p. 39-64.

BOURDIEU, Pierre [1979]. Os três estados do capital cultural. In: NOGUEIRA, Maria Alice; CATANI, Afrânio (Orgs.). Pierre Bourdieu: escritos de educação. 8. ed. Petrópolis: Vozes, 1998. p. 71-79.

BOURDIEU, Pierre; PASSERON, Jean-Claude. Los estudiantes y la cultura. Tradução: María Teresa López Pardina. Barcelona: Editorial Labor, 1967.

CANDIDO, Antônio. Literatura e sociedade. São Paulo: Nacional, 1980.

DE SINGLY, François. Savoir hériter: la transmission du goût de la lecture chez les étudiants. In: FRAISSE, Emmanuel (Org.). Les étudiants et la lecture. Paris: PUF, 1993. p. 49-71.

DE SINGLY, François. L'appropriation de 1'heritage culturel. Lien Social et Politiques - RIAC, n. 35, p. 153-165, 1996.

GALVÃO, Ana Maria de Oliveira. Oralidade, memória e a mediação do outro: práticas de letramento entre sujeitos com baixos níveis de escolarização - o caso do cordel 
MELO, J. F. de; GALVÃO, A. M. O. Ler e escrever, ver, ouvir e contar histórias em família...

(1930-1950). Educação e Sociedade, São Paulo, Dossiê “Letramento”, v. 23, n. 81. p. 115-160, dez. 2002.

GALVÃO, Ana Maria de Oliveira; BATISTA, Antônio Augusto Gomes. Oralidade e escrita: uma revisão. Cadernos de Pesquisa, São Paulo: Fundação Carlos Chagas, v. 36. n. 128, p. 403-432, maio/ago. 2006.

GALVÃO, Ana Maria de Oliveira et al.(Orgs.). História da cultura escrita: séculos XIX e XX. Belo Horizonte: Autêntica, 2007.

GALVÃO, Ana Maria de Oliveira. História das culturas do escrito: tendências e possibilidades de pesquisa. In: MARINHO, Marildes; CARVALHO, Gilcinei Teodoro (Orgs.). Cultura escrita e letramento. Belo Horizonte: Editora UFMG, 2010. p. 218-248.

GINZBURG, Carlo [1976]. O queijo e os vermes: o cotidiano e as idéias de um moleiro perseguido pela Inquisição. Tradução: Maria Betânia Amoroso; tradução dos poemas: José Paulo Paes. São Paulo: Companhia das Letras, 2006.

HEATH, Shirley B. Ways with words: language, life, and work in communities and classrooms. New York, NY: Cambridge University Press, 1983.

HÉBRARD, Jean. O autodidatismo exemplar. Como Valentin Jamerey-Duval aprendeu a ler? In: CHARTIER, Roger (Org.). Práticas de leitura. São Paulo: Estação Liberdade, 1996. p. 35-74.

HÉBRARD, Jean. Três figuras de jovens leitores: alfabetização e escolarização do ponto de vista da história cultural. In: ABREU, Márcia (Org.). Leitura, história e história da leitura. São Paulo: Mercado de Letras, 2000. p. 33-78.

HÉBRARD, Jean. Alfabetização e acesso às práticas da cultura escrita de uma família do sul da França entre os séculos XVIII e XIX: um estudo de caso. In: GALVÃO, Ana Maria de Oliveira et al. (Orgs.). História da cultura escrita: séculos XIX e XX. Belo Horizonte: Autêntica, 2007.

LAHIRE, Bernard. Retratos sociológicos: disposições e variações individuais. Tradução: Didier Martin; Patrícia Chittoni Ramos. Porto Alegre: Artmed, 2004.

LAHIRE, Bernard. A cultura dos individuos. Tradução: Fátima Murad. Porto Alegre: Artmed, 2006.

MAGALDI, Ana Maria Bandeira de Mello. Lições de casa: discursos pedagógicos destinados à família no Brasil. Belo Horizonte: Argumentum, 2007.

MAUAD, Ana Maria. Na mira do olhar: um exercício de análise da fotografia nas revistas ilustradas cariocas, na primeira metade do século XX. In: Anais do Museu Paulista. n. 1, v. 13. São Paulo: Universidade de São Paulo, 2005. p. 133-174. Disponível em: $<$ http:// redalyc.uaemex.mx/redalyc/pdf/273/27313105.pdf>. Acesso em: 31/07/2008.

MEYER, Marlyse. Folhetim: uma história. São Paulo: Companhia das Letras, 1996. 
NOGUEIRA, Maria Alice. Famílias de camadas médias e a escola: bases preliminares para um objeto em construção. Educação e Realidade, Porto Alegre, v. 20, n. 1, p. 9-25, jan.jul. 1995.

NOGUEIRA, Maria Alice. Convertidos e oblatos: um exame da relação classes médias/ escola na obra de Pierre Bourdieu. Educação, Sociedade e Culturas, Porto, n. 7, p. 109129, maio 1997.

NOGUEIRA, Maria Alice; CATANI, Afrânio (Orgs.). Pierre Bourdieu: escritos de Educação. 8. ed. Petrópolis: Vozes, 1998.

NOGUEIRA, Maria Alice; ROMANELLI, Geraldo; ZAGO, Nadir (Orgs.). Família e escola: trajetórias de escolarização em camadas médias e populares. Petrópolis: Vozes, 2000.

RIBEIRO, Vera Masagão (Org.). Letramento no Brasil: reflexões a partir do INAF 2001. São Paulo: Global, 2003.

SOARES, Magda. Letramento: um tema em três gêneros. 2. ed. Belo Horizonte: Autêntica, 1998.

SOARES, Magda. Letramento e escolarização. In: RIBEIRO, Vera Masagão (Org.). Letramento no Brasil: reflexões a partir do INAF 2001. São Paulo: Global, 2003. p. 89-113.

VERGUEIRO, Waldomiro; SANTOS, Roberto Elísio dos. O Tico-tico: centenário da primeira revista de quadrinhos do Brasil. São Paulo: Ópera Graphica, 2005.

ZUMTHOR, Paul. A letra e a voz: a "literatura" medieval. Tradução: Amálio Pinheiro; Jerusa Pires Ferreira. São Paulo: Companhia das Letras, 1993.

Texto recebido em 16 de setembro de 2014.

Texto aprovado em 23 de setembro de 2014. 
